\title{
Object Sorting and Stacking Automation With PLC
}

\author{
Prof Dhaval Tailor ${ }^{\# 1}$, Vivek Kamani ${ }^{\# 2}$, Ankit Ghetiya ${ }^{\# 3}$, Naresh Bhatiya ${ }^{\# 4}$ \\ \#1 Department of Electrical Engineering, A. D. Patel Institute of Technology,New V V Nagar, India \\ \#2 Department of Electrical Engineering, A. D. Patel Institute of Technology, New V V Nagar, India \\ \#3 Department of Electrical Engineering, A. D. Patel Institute of Technology, New V V Nagar, India \\ ${ }^{\# 4}$ Department of Electrical Engineering, A. D. Patel Institute of Technology, New V V Nagar, India \\ "1 tailordhaval@gmail.com, ${ }^{\# 2}$ vivekkamani10@gmail.com \\ \#3ankitghetiya@gmail.com, "\#4nareshbhatiya08@gmail.com
}

\begin{abstract}
In recent years there is a considerable growth and development in the field of automation both in industry and residential areas. The production rates of industries have considerably increased in recent years leading to the shortage of labours. Industries generally manufacture same type of products with little variation in size, colour, weight and shape. Here sorting of defective object plays an important role as these industries cannot afford any human errors for sorting products. Thus, it becomes absolutely necessary to develop a system that could sort these objects without any human interference $\&$ in accurate manner. Automation industries focuses on developing automation having long durability, low cost, less maintenance, and to make system as user friendly as possible. Thus, we have developed a system for sorting object with any metallic impurities using sensor and motor controlled by Programmable Logic Controller(PLC) and the conveyor in the system passes the object through sensors and hence sorting logic is decided.
\end{abstract}

Keywords: Automation, PLC, Sorting, Stacking

\section{INTRODUCTION}

The new development in manufacturing industry is greatly dependent upon the research in the manufacturing sector and innovation in new products. The countries having high rate of production and quality are marked as developed whereas those countries with low production rates are underdeveloped ${ }^{[2]}$.

During processing, the raw material gets transformed into product. Once this product gets processed it earns a value for sale. Therefore, manufacturing is 'adding value' to the material. The value that is earned by the product should have more cost allowing the organization to make money out of it ${ }^{[1]}$. Industries generally manufacture same type of products with little variationin size, colour, weight and shape hence sorting plays an important role. In earlier days when demand was less it was possible to use manual labour for sorting similar object, but now with increase in demand and production industries can't afford human errors for sorting these products.This scenario forced the industries to adopt automation of the sorting and packing process. Proper storing of finished goods is also important for the industry. Boxes are stacked in the warehouses and this process also requires large amount of labours, automation in this area helps to ease the process. In developing any industry economy is the main factor that is considered, hence it is necessary to make cost effective automation system which is affordable ${ }^{[2]}$. Also, system should be able to enhance productivity and remove defective object accurately is necessary. The stacking should be done properly without any failure.

In this project, we have developed a cost-effective automation system for sorting lightweight objects for any metallic impurity. The projects main focus is on the removal of impure objects and stacking of the boxes in the stand. This whole process is done automatically with the help of PLC ${ }^{[4]}$. DC motor is used for pushing the object form the conveyor belt into the recycling bin. The system consists of two conveyor belts for taking object and boxes, and the stacking mechanism consisting of lift and the stand for placing boxes. Conveyor belt brings the objects near the sensor and hence logic for PLC is decided. The PLC is programmed for sorting, counting and stacking of the objects. The system consists of four IR sensors for signalling the PLC and detect the presence of object and boxes. Counting of object is also done with the help of this sensor. The metallic defect is detected with the help of proximity sensor. In our project, we have used two conveyors, product conveyor and box conveyor $^{[5]}$. We have focused on developing product conveyor and stacking model. Whole system uses DC motors for powering. These motors are interfaced with the PLC through relay cards. Sensors are placed on the metal plates and proximity sensor is hanged from above. One sensor is mounted on the placing mechanism of the stacker lift. This sensor will detect the presence of the boxes that were already kept there. 


\section{LITERATURE REVIEW}

Nowadays manufacturing industries has started using automation and robotics to increase their production as well as quality of their goods. In old days' robotics used to play a vital role in the industrial automation to reduce human effort and time required for the production. Everything ranging from painting, machining, packing, stacking, sorting was either done by robots or human labours.

Real time and highly accurate sorting of objects in a fast-flowing stream would open new directions for industrial automation process. Recent advances in electronics and printed circuit board technology open new perspectives for industrial application in this field. ${ }^{[2]}$

Currently used system in the industry are being modified according to the budget and scope of the industry. Existing system includes processes based on microcontroller, pneumatic, robotics or sensor based. Use PLC has started but on the smaller scale due to complexity in the installation.

\section{SYSTEM BUILDING AND OPERATION}

In our project, we have developed a tail end of the industrial process which had required large amount of labour power to smoothly operate. But with the coming of automation this requirement has decreased, since here we have also modified stacking process \& has made it automatic so it will also require less labour to operate. Moreover, it's working and operating capability will also increase considerably.

Here we have used two conveyor belt one for the products and other for the boxes in which these products will fill. This conveyor will lead the box to the platform which will be lifted and will be placed in the loading area where these boxes will be arranged automatically in the stand. These conveyors and lift will all be driven by DC motor with 12V 7amp battery. These motors will be interfaced with PLC through 24V relay.

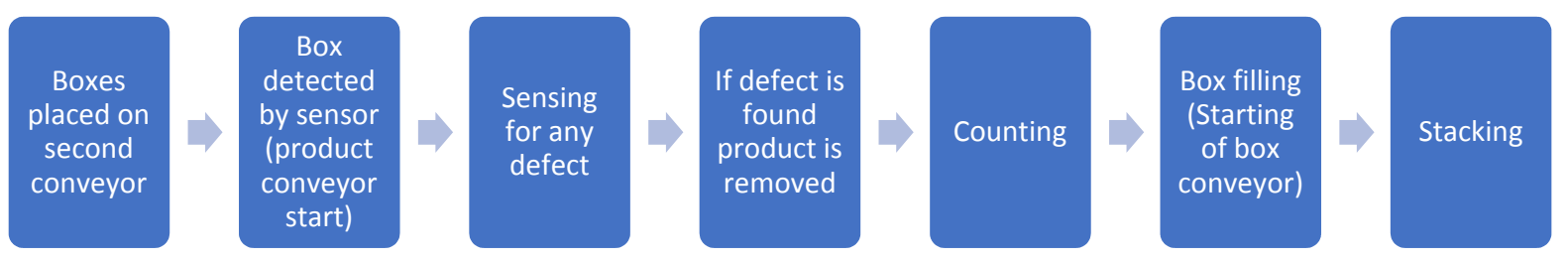

This system uses two different types of sensors for sensing objects and boxes to help PLC work properly. These sensors include four 24V IR sensors and one proximity sensor which will detect any defect present in the object passing under it. These sensors are mounted on metal stands across the conveyor belts from where the data will be required to take action.

First IR sensor will be mounted at the stating of box conveyor, this sensor will start the belt, latch will be inserted to keep this belt on ${ }^{[6]}$. Second IR sensor will be placed exactly opposite to product conveyor to stop the box. This sensor will sense the presence of box, only then the product conveyor will start. This will ensure that the product fall directly into the box and none of the product is wasted. Third IR sensor will do the job of counter as fixed number of object should be placed in the box for packing, this sensor will be mounted on one of the holding plated near the end of product conveyor. Main sensor for detecting defect, will be mounted above the product belt, below which the products pass and will detect for any metallic defect. Fourth IR sensor is mounted on the lifting platform, this sensor detects the presence of any previously placed box in the stand. This avoids any accident in placing the packed boxes.

The pusher consists of DC motor powered by 9V battery. It will have a pushing plate which will be activated when any defective object is detected and it will be powered by small DC motor. Forward and reverse movement of the pusher is done in the PLC ladder logic.

When the box is placed at box conveyor by the operator the box is sensed by sensor 1 and it will signal PLC to start box conveyor. This carries the box towards the filling area, as the box reaches exactly in front of product belt second sensor will activate and signals PLC to stop running belt and start product conveyor. As product starts moving towards the box they are scanned for any defect or impurities present in them by the proximity sensor. If any impurity is found, sensor will give signal to PLC to stop the product belt and activated the pushing mechanism which removes the defective product. After this operation, again product conveyor will start and product moves forward. When they reach the end of the belt, here sensor three will count the number of objects falling into the box. When the fix number of objects are passed, sensor will signal PLC to stop the product belt and start the box conveyor. As filled box moves forward another empty box behind will cut the sensor 2 and the process of sorting and filling is repeated. This process continues till the filled box is reached the lifting platform, here the fourth sensor gives command to PLC for stopping all the process till stacking of box is complete. 
When fourth sensor is cut, lift is activated which is a chain drive system. It lifts the filled box upward till the place for its placing is reached. If sensor detects that no box is placed prior to this then it will place the box in the empty space. Here also forward reverse mechanism is used to move platform back and forth for placing the box. After placing, the lift will return to its original position and sensor will signal PLC to continue the previously stopped process. PLC used in our project is made by Delta Electronics India. It has 24 input and 24 output digital pins and 8 input output analog pins.

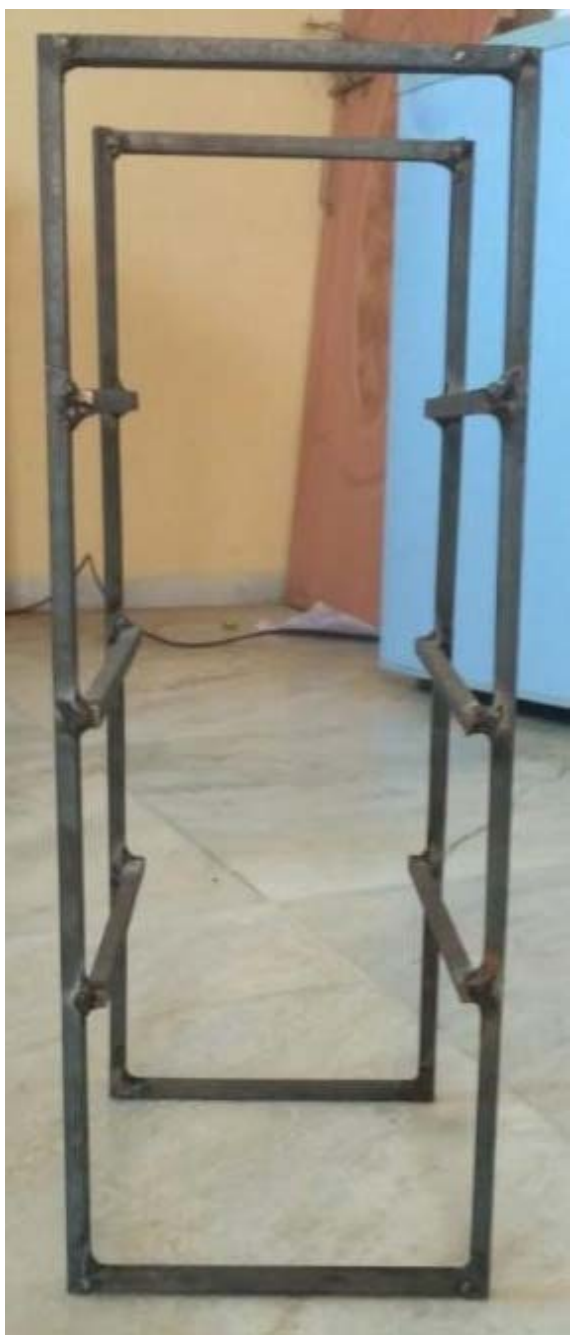

Fig:1 Box Stand

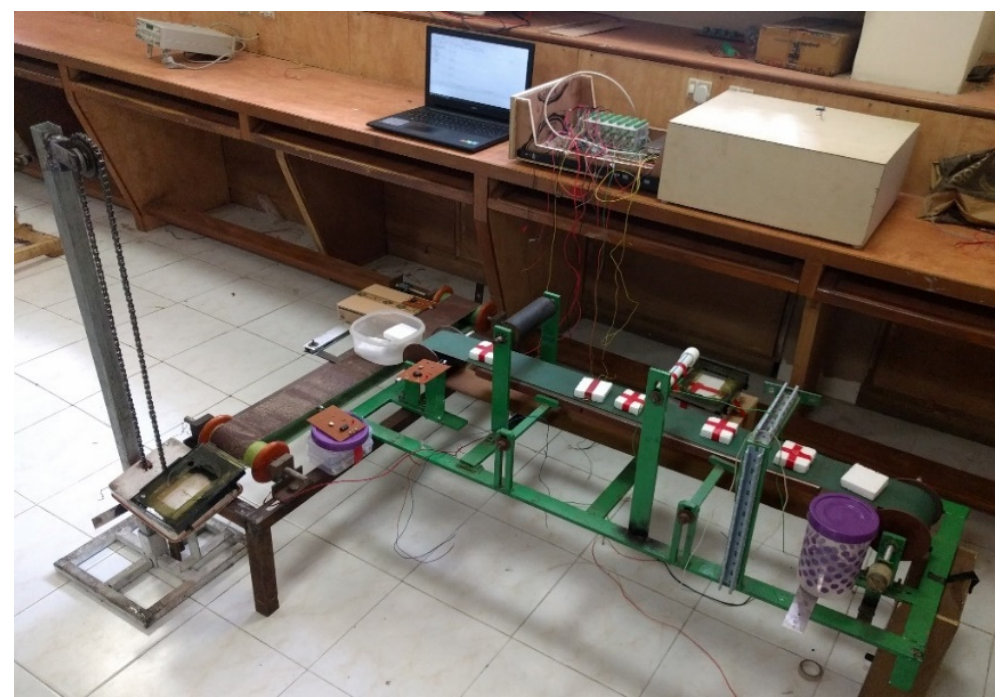

Fig:2 Complete Structure

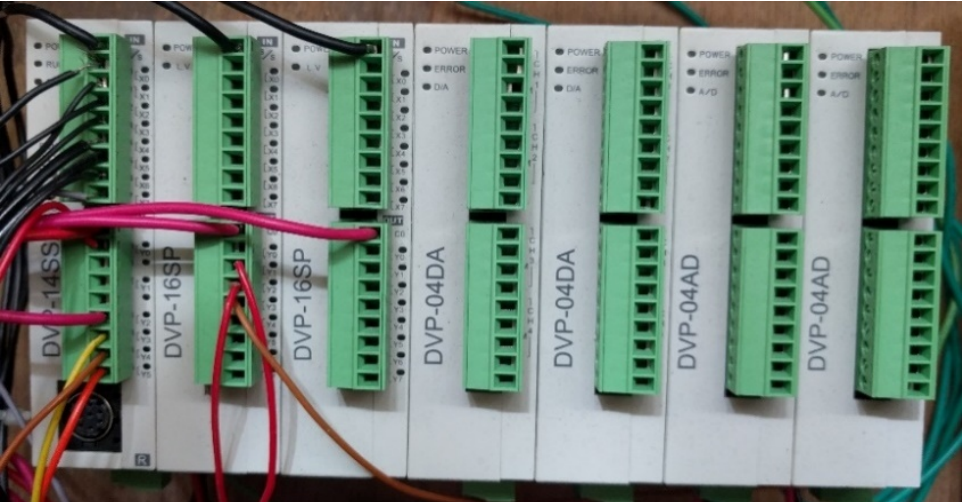

Fig:3 Delta PLC 


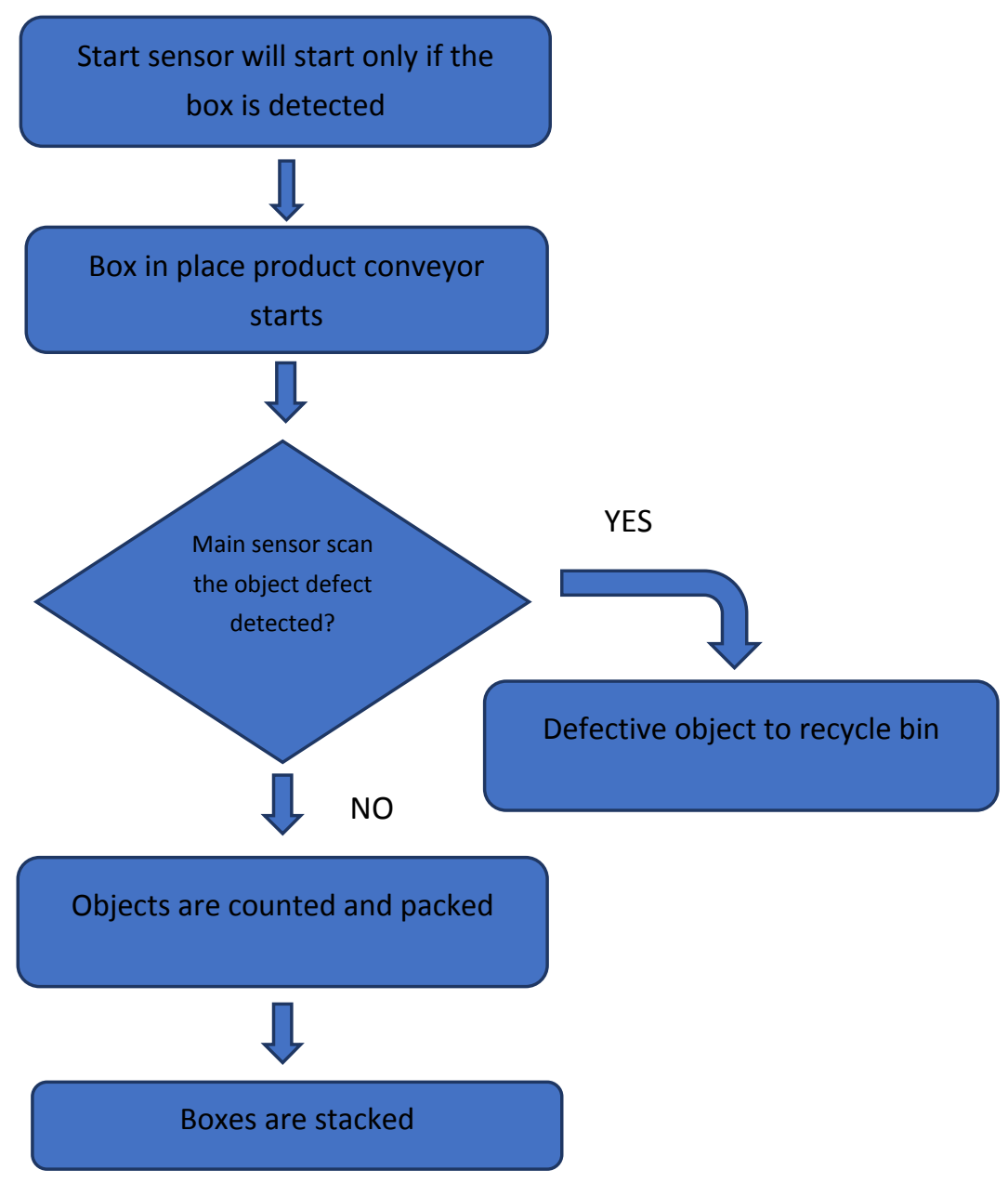

\section{A. FLOWCHART DESCRIPTION}

1. Box is placed on the box conveyor and the sensor is cut, gives signal to PLC to start the belt.

2. Box moves forward and reaches sensor 2, gives signal to PLC to stop box belt and start product belt thus identifying it as box in place.

3. Main sensor scans the product for any defect or impurity and if any found pushes the product into recycle bin. If no defect is found then product moves forward.

4. At the end of product belt the sensor counts the number of products falling into the box. As predefined number reaches box moves forward and is packed.

5. When box reaches stacking platform the lift will place the box at the desired place in the stand.

\section{PERFORMANCE ANALYSIS OF THE SYSTEM}

Performance analysis includes the performance of the device with various inputs and by using different topologies applying to the device. Mitsubishi 1000 Nexgenie PLC require CoDeSys software for coding purpose. The PLC and computer is connected by a RS232 cable. The programming of the PLCcan be perform in 3 different languages. Out of which ladder diagram is preferable as it provides easy electrical circuit representation and after development of the ladder logic it can be converted to secured code such as STL ${ }^{[3]}$. 
V. COMPARISON OF NEW AND EXISTING SYSTEMS

\begin{tabular}{|l|l|l|}
\hline & \multicolumn{1}{|c|}{ OLD SYSTEM } & \multicolumn{1}{|c|}{ NEW DEVELOPED SYSTEM } \\
\hline 1. & Defects were checked manually. & Sensors are used to detect defects. \\
\hline 2. & Time consuming and required more labours. & $\begin{array}{l}\text { System is faster and human effort is greatly } \\
\text { reduced. }\end{array}$ \\
\hline 3. & $\begin{array}{l}\text { Counting and packing was difficult due to } \\
\text { manual process and sometimes erroneous due to } \\
\text { crude technology. }\end{array}$ & $\begin{array}{l}\text { Counting is automatic and effortless also it is } \\
\text { accurate. }\end{array}$ \\
\hline 4. & $\begin{array}{l}\text { Stacking of packed goods created lot of problem } \\
\text { especially heavy goods. }\end{array}$ & $\begin{array}{l}\text { Stacking is automatic and PLC controlled hence } \\
\text { no human effort is required. }\end{array}$ \\
\hline 5. & $\begin{array}{l}\text { Overall process was either done manually or } \\
\text { used outdated technology resulting in accidents } \\
\text { and errors. }\end{array}$ & $\begin{array}{l}\text { Process is automated and chances of errors are } \\
\text { negligible. }\end{array}$ \\
\hline
\end{tabular}

\section{CONCLUSION}

In the earlier systems when the technology was not reliable to make processes completely automatic as they had many problems and failure, due to this drawback human intervention was required at every stage in the manufacturing process in the industry. This resulted in the time and production loss due to human and machine errors. But as the development in the technology took place sophisticated instruments and sensor are being used to reduce human interference and increase efficiency. In our project, we have built the system which can identify defective object count number of objects and fill them in the box, these boxes are stacked automatically. Whole process is automated and only one operator is required to monitor the process. This system automated using PLC and sensors.

\section{REFERENCES}

[1] Manjunatha "Postal Automation System for Mail Sorting” International Journal of Emerging Technology and Advanced Engineering (ISSN 2250-2459) Volume 5, Issue 3, March 2015

[2] Prof. Nilima Bargal Aditya Deshpande, Rucha Kulkarni, Rucha Moghe "PLC Based Object Sorting Automation” International Research Journal of Engineering and Technology (IRJET) (ISSN: 2395 -0056) Volume: 03, Issue: 07, July 2016

[3] D. A. Wahab, A. Hussain, E. Scavino, M.M. Mustafa and H. Basri "Development of a Prototype Automated Sorting System for Plastic Recycling” American Journal of Applied Sciences 3 (7): 1924 -1928, 2006 ISSN 1546-9239 @ 2006 Science Publications

[4] Albert T. Jones, Charles R. McLean, "A proposed hierarchical control model for automated manufacturing systems", National Bureau of Standards, Gaithersburg, Maryland, USA.

[5] Y V Aruna, Beena S “Automatic convey or System with In-Process Sorting Mechanism using PLC and HMI System”, Int. Journal of Engineering Research and Applications ISSN: 2248-9622, Vol. 5, Issue 11, (Part -3) November 2015, pp.37-42

[6] Saurin Sheth,Rahul Kher, Rushabh Shah, Parth Dudhat, Pratyush Jani "Automatic Sorting System Using Machine vision”, DOI: 10.13140/2.1.1432.1448 Conference: Multi-Disciplinary International Symposium on Control, Automation \& Robotics, At DDIT, Nadiad, Volume: 1

\section{AUTHOR PROFILE}

Prof. Dhaval N Tailor working as an Assistant Professor in Electrical Engineering Department, A. D. Patel Institute of Technology, New V V Nagar, India.

Vivek Kamani is pursuing B.E. Electrical Engineering Department, A. D. Patel Institute of Technology, New V V Nagar, India.

Ankit Ghetiya is pursuing B.E. Electrical Engineering Department, A. D. Patel Institute of Technology, New V V Nagar, India.

Naresh Bhatiya is pursuing B.E. Electrical Engineering Department, A. D. Patel Institute of Technology, New V V Nagar, India. 